\title{
The Curative HCV Treatments in China
}

\author{
Yifan Fei ${ }^{*}$, Jiawen Jiang ${ }^{2 * \#}$ \\ ${ }^{1}$ China Agricultural University, Beijing, China \\ ${ }^{2}$ Dalian No.24 High School, Dalian, China \\ Email: "jia ngjw0705@outlook.com
}

How to cite this paper: Fei, Y.F. and Jiang, J.W. (2018) The Curative HCV Treatments in China. Journal of Biosciences and Medicines, 6, 42-59. https://doi.org/10.4236/jbm.2018.68004

Received: June 5, 2018

Accepted: August 6, 2018

Published: August 9, 2018

Copyright $\odot 2018$ by authors and Scientific Research Publishing Inc. This work is licensed under the Creative Commons Attribution International License (CC BY 4.0).

http://creativecommons.org/licenses/by/4.0/

(c) (i) Open Access

\begin{abstract}
Hepatitis $\mathrm{C}$ disease is caused by hepatitis $\mathrm{C}$ virus (HCV) which causes chronic infections in about 180 million individuals worldwide. HCV has been identified as the etiologic agent of hepatitis C in 1989 and for the longest time it is very difficult to treat chronic carriers who are at risk of developing severe liver disease. Now there are three main combined treatments which can increase curative ratio from $10 \%$ to more than $90 \%$. The advents of so called directly, acting antivirals (DAAs) in the last few years has revolutionized HCV treatment as these drug combinations can effectively cure HCV in the great majority of patients. The impact of DAAs on global disease burden has been limited, however, by the very drug prices. In this paper the situation was analyzed in China, Europe and Australia. DAAs have been made available to patients in Europe and Australia for several years and are generally accessible. The treatment is highly subsidized by the government, thereby making it possible for all patients in need to access therapy. DAAs have only been very recently been adopted for treatment of chronic hepatitis $C$ in China. In our research, only the method of literature search from both Chinese websites and Foreign websites including journals, magazines and internet search is used. We analyze and compare the solutions that each of these countries is providing to their respective patient populations. Given the large number of chronic HCV carriers in China and other less developed countries solutions have to be found to produce DAAs most cost effectively.
\end{abstract}

\section{Keywords}

HCV, DAA, China, Australia, Europe

\section{Introduction}

\subsection{Hepatitis $C$}

\subsubsection{Prevalence}

Hepatitis C, caused by hepatitis C virus (HCV) significantly contributes to mor-

${ }^{\star}$ Contributed equally, signature by the alphabetical order of names. 
tality and morbidity in the human population. Approximately, 177.5 million people are estimated to be infected with HCV globally [1] (Burstow et al., 2017). Though several studies show that the infection of HCV has decreased since the second half of the 20th century, there are still about 1.75 million people get infected each year [2] (Global Hepatitis Report, 2017). HCV affects all regions and the type of virus has major differences among different regions. According to the 2017 global hepatitis C report of World Health Organization (WHO), in 2015, the global prevalence of HCV infection was $1.0 \%$. The Eastern Mediterranean Region recorded the highest prevalence (2.3\%) and the second was the European Region (1.5\%) in 2015 [2] (Global Hepatitis Report, 2017). Since HCV is a blood-borne virus. Its prevalence is mainly caused by contaminated blood products, unsafe injection use, mother to child transmission and sexual transmission.

\subsubsection{Basic Impacts of Getting Infected by HCV}

The acute HCV affection is usually asymptomatic. Under certain circumstance it may cause malaise, nausea, and right upper quadrant pain, and in more serious circumstances, it may lead to dark urine and jaundice. But only according to these not specific symptoms, it is still very difficult to distinguish HCV infection from any other acute viral hepatitis [3] (Tyagi et al., 2017). About 70\% - 80\% acute HCV affection will finally progress to chronicity. Only approximately $20 \%$ - 30\% acute infections can cure spontaneously [4] (Ray, S.C. et al., 2013). Studies have shown that young women are more likely to resolve the infection [5] (Seeff, 2002). Chronic HCV infection frequently results in progressive liver disease. $5 \%$ - $20 \%$ of chronic carriers will progress to cirrhosis after approximately 25 years [4] (Stuart et al., 2013). The disease also links to fibrosis and hepatocellular carcinoma (HCC) [5] (Seeff, 2004). After that, the process of some cirrhosis will slow and $10 \%$ to $20 \%$ will decompensate clinically within 5 years. At this stage, the patient may have some signs indicating chronic liver disease like caput medusae, spider angiomas, palmar erythema, asterixis, anasarca, fluid thrill [3] (Tyagi et al., 2017). This slow development of hepatitis $\mathrm{C}$ can be accelerated by heavy alcohol intake and co-infection [6] (Hajarizadeh et al., 2013). Chronic HCV infection is one of the leading causes of death among human immunodeficiency virus (HIV) infected people [7] (Koziel et al., 2007). HCV can also co-infect with hepatitis B virus (HBV). Furthermore, HIV/HBV co-infection is associated with accelerated fibrosis progression and cirrhosis [3] (Tyagi et al., 2017). Special regiments need to be made to treat the co-infection patients.

\subsubsection{Hepatitis C Virus}

In 1989 Choo and colleagues identified HCV as the etiologic agent of so called non-A non-B hepatitis, which was later renamed as hepatitis $\mathrm{C}$. As HCV is as similar as the structure and function of flaviviruses, it is classified as part of the Flaviviridae family, genus hepacivirus. Based on sequence analysis at least 7 distinct HCV genotypes have been defined, which have different prevalence across the globe [8] [9] (Miao et al., 2017) (Murphy et al., 2016). In each patient there 
are numerous genetic variants, referred to quasispecies that are generated during the highly error-prone replication process.

The structure of HCV makes CHC a worldwide disease difficult to treat. Currently, the drug such as DAA can effectively suppress the viral replication which mainly target on the loophole in the structure of HCV. HCV is a small particle with 55 - $65 \mathrm{~nm}$ in size (see Figure 1) ( $\mathrm{HCV}$ in liver is $80 \mathrm{~nm}$ in size, while in blood is $36-40 \mathrm{~nm}$ in size). It is enveloped with glycoprotein, and constituted by a positive single-strand RNA genome as its hereditary material in its core, which surrounded by an icosahedral protected shell of protein-the viral nucleocapsid. The capids is surrounded by a host derived membrane in which the viral E1 and E2 glycoproteins are incorporated [10] (Simmonds et al., 1993).

The HCV genome is approximate $10 \mathrm{~kb}$ in length and can be distinguished in coding and non-coding regions. The so called untranslated regions (UTR) in the viral genome at the 5 and 3 ends of the viral RNA are not translated into proteins but are vital to translation and replication process of the RNA. The ribosome binding site that begins the translation process of a polyprotein contains approximately 3000 amino acids. This kind of polyprotein is processed by proteolytic enzymes into 4 structural (core, E1, E2, p7) and six non-structural (NS2, NS3, NS4a, NS4b, NS5a, NS5b) proteins [10] (Simmonds et al., 1993).

HCV's exclusive replicative reservoir in the human body is the hepatocyte. As viral particles enter human body, LDLR is hydrolysed by LPL and with the help of lipase to transform VLDL to LDL. LVPs then interact with the scavenger receptor class B member1 (SR-BI), due to relatively elevated affinity to exposed E2. Two tight junction proteins, claudin-1 (CLDN1) and occludin (OCLN) are crucial for HCV uptake that is eventually facilitated through receptor mediated endocytosis. The endosome containing viral particles is subsequently acidified leading to conformational changes in the viral envelop proteins which induce fusion of the viral with the endosomal membrane. Thereby, the viral nucleocapids is released into the cytoplasm where it starts to disassemble liberating the viral RNA. For HCV assembly, viral particles are assembled in close association with lipid droplets. Viral particles associate closely with host derived lipoproteins and notably APOE, forming so called lipoviroparticles. AP-2-associated protein kinase 1 (AAK1) and the association with cyclin G-associated kinase (GAK) assembly independently on entering the host cell by controlling AP-2binding to the protein in the core of $\mathrm{HCV}$, which is on lipid droplets (see Figure 2 and Figure 3). HCV particles are released along the very low density lipoprotein excretion pathway.

\subsection{Antiviral Therapies}

\subsubsection{Pre-DAA Era}

\section{1) Interferon-alpha}

Interferons (IFNs) are signaling proteins that are produced and secreted by host cells during microbial infection [11] (De Andrea et al., 2002). Type I IFNs including IFN-beta and various forms of IFN-alphas are a subclass of cytokines 


\section{envelope glycoproteins}

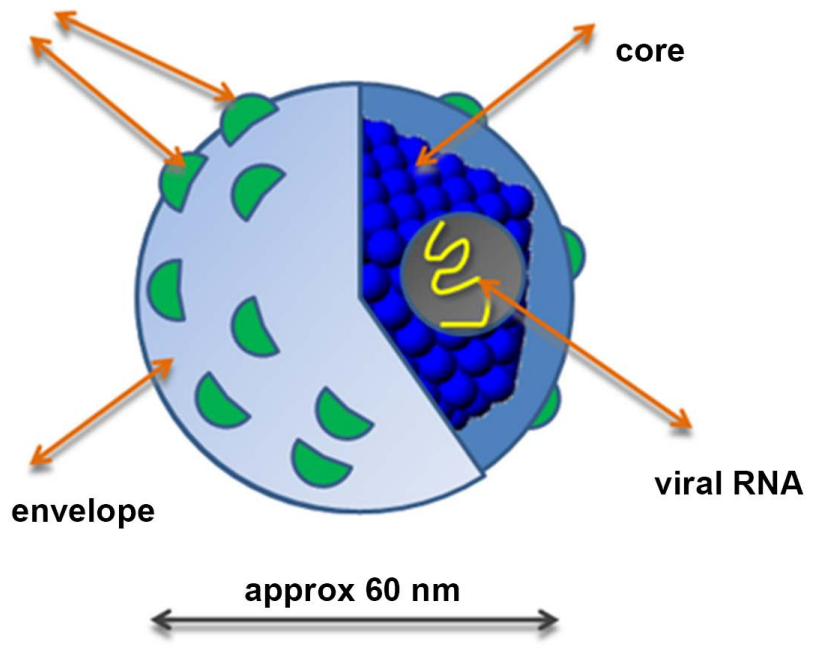

Structure of Hepatitis C Virus

Figure 1. A simplified figure about the main structure of HCV [8] (Simmonds et al., 1993).

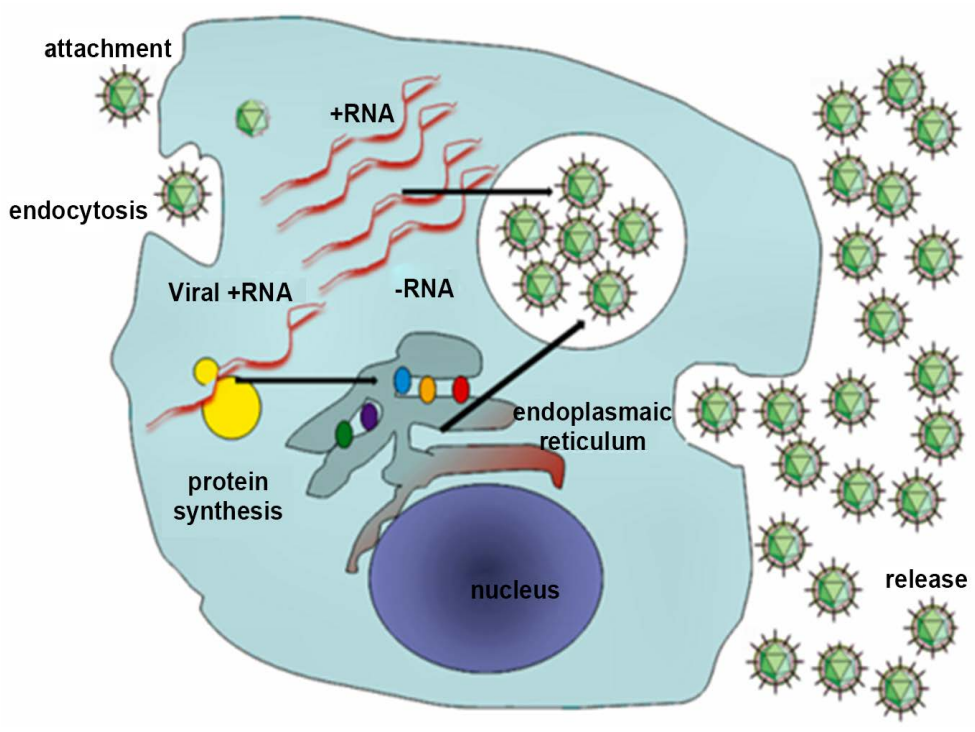

Figure 2. This figure shows the simplification of the process which HCV enter, replicate, and release the body cell [10] (Murphy et al., 2016).

and can intensify antiviral defense of hosts through interrupting viral reproduction, activating immune cells such as natural killer cells and macrophages and up-regulating MHC antigens [12] (Cohen et al., 2001).

IFNs are released as a result of viral infection recognition, inducing actions of a series of enzymes such as protein kinase R (PKR), eIF-2 and RNASE L to inhibit protein synthesis hence destroying the virus and infected host cells. IFNs induce the production of interferon-stimulated genes (ISGs), proteins that combat viruses and participate other interferon actions [13] [14] (Fensterl et al., 2010) (De Veer, 2001). In addition, p53 activity increases because of IFNs, promoting 


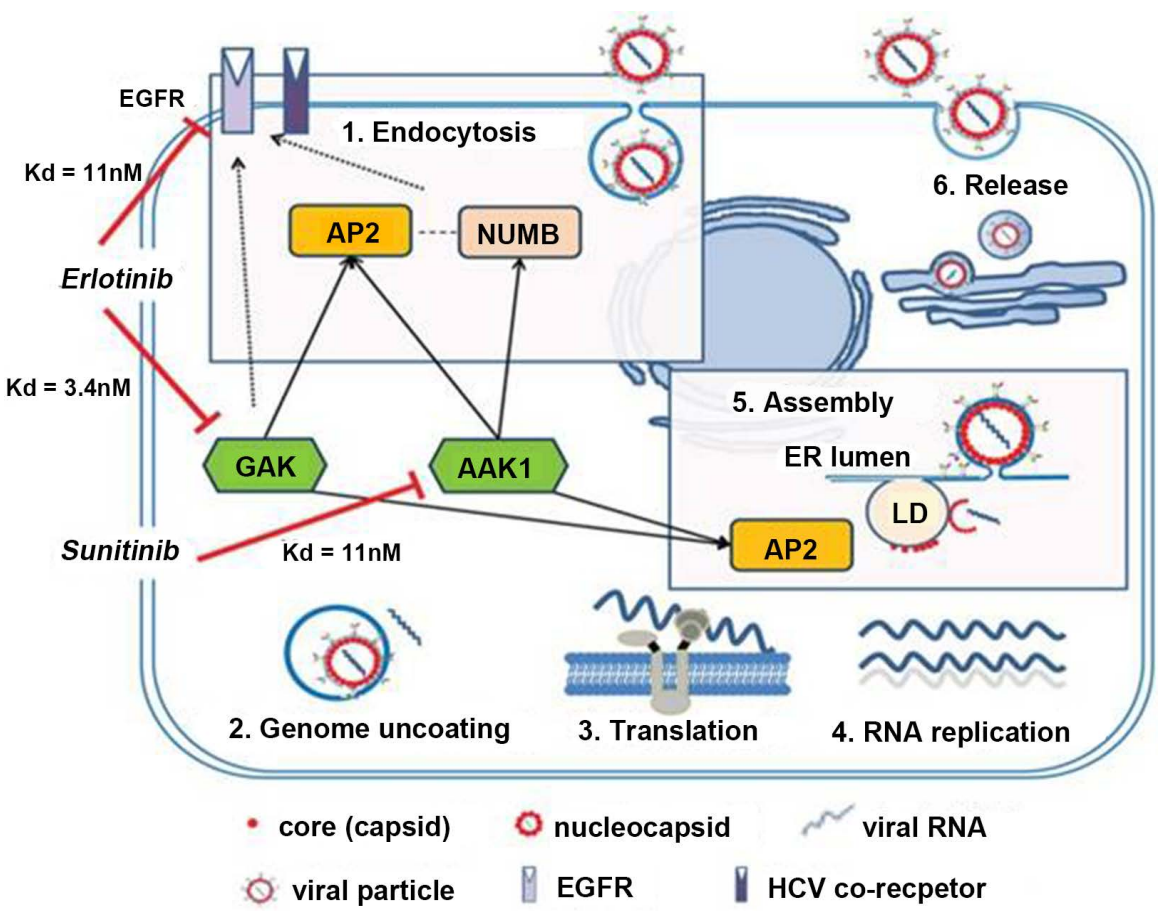

Figure 3. This figure is a more detailed graph about how virus entry, replicate and release the host cell in a human body [8] (Simmonds et al., 1993).

apoptosis and restricting viral spread [15] (Moiseeva et al., 2006). IFNs can also contribute to antiviral defense through activating other immune cells directly or upregulating MHC I and MHC II expression, improving antigen presentation to cytotoxic $\mathrm{T}$ cells and helper $\mathrm{T}$ cells.

Before the introduction of DAAs IFN-alpha $2 a$ or $2 b$, subtypes of IFN, were the first usable treatment for HCV, which was a 24-or 48-week course of genotype-dependent treatment regimen, injected three times a week [16] (National Institutes of Health Consensus Development Conference, 1997), with a rate of viral clearance less than 10\% [17] (Carithers et al., 1997). Later, IFN-alpha combined with ribavirin (RBV) therapy enhanced the sustained virological response (SVR) rates to about 30\% - 40\% [18] (McHutchison et al., 1998). Until 2011, pegylated interferon (PEG-IFN)-alpha $2 \mathrm{a}$ and $2 \mathrm{~b}$ together with RBV existed as the standard of care for chronic hepatitis C (CHC) [19] (European Association for the Study of the Liver, 2011), taking 24- or 48-week course and one injection each week [20] (Di Bisceglie et al., 2002). The SVR rate of genotype 2 (GT2), GT3, GT5, GT6 also rose to 80\% [21] [22] (European Association for the Study of the Liver, 2015) (Antaki, 2010). But the SVR rate of CHC CT1, which is the most infected GT all around the word, was approximately $40 \%$, a lot lower comparing with other GTs [18] [23] (McHutchison et al., 1998)(Fried et al., 2003). Additionally, the usage of PEG-IFN plus RBV triggers a variety of contraindications in patients with different defects, autoimmune disease and psychosis included [16] (National Institutes of Health Consensus Development Conference, 1997). 


\section{2) Ribavirin}

Ribavirin (RBV) is a hepatitis $\mathrm{C}$ antiviral medication. It is taken orally and is usually administered in combination with PEG-IFN alpha-2b or PEG-IFN-2a [24] (The American Society of Health-System Pharmacists, 2016). When incorporated into RNA, RBV is able to interfere with viral replication since it is a base analog of adenine or guanine, which enables its equally-well pairing with uracil or cytosine including RNA-dependent replication mutations in RNA viruses, resulting in the elimination of RNA viruses. However, opinions on details of ribavirin action mechanism remain controversial [25] [26] (Ortega-Prieto et al., 2013) (Crotty et al., 2002).

RBV derived its patents in 1971 and was produced in 1972 for the first time by researchers from International Chemical and Nuclear Corporation [27] [28] (Fischer et al., 2006) (Snell et al., 2001). Medical use permission was conferred to RBV in 1986 [29] (Hézode et al., 2013). The combination of PEG-IFN and RBV acted as the standard of care for chronic HCV infection raising the SVR rate of hepatitis C GT 1 to $40 \%-50 \%$ and the SVR rate of GT 2 and 3 to $70 \%-80 \%$, which was a significant improvement compared with using IFN alone as the HCV treatment [29] (Hézode et al., 2013). Although RBV is an effective medication for hepatitis $\mathrm{C}$, it still induces several contraindications such as renal failure, rash, cough, hemolysis and teratogenesis, so PEG-IFN combined with RBV therapy is ineligible for some patients [30] [31] (Bruchfeld et al., 2003) (Ward et al., 2005).

\subsubsection{Direct-Acting Antivirals (DAAs)}

Given the relatively low cure rate and unwanted side effects brought by IFN and RBV regimens for hepatitis $C$, a more effective therapy was needed, which is DAAs that target particular HCV replication-involved proteins [32] (Schinazi et al., 2014).

The era of DAAs began in May 2011, when first-generation of NS3/4A protease inhibitors, boceprevir (BOC) and telaprevir (TVR), was approved for use in HCV G1 combined with PEG-IFN and RBV [33] [34] [35] (Kwo et al., 2010) (Poordad et al., 2011) (Jacobson et al., 2011). Although the improvement of SVR made by BOC and TVR was remarkable, from $40 \%$ to $75 \%$ in GT1 treatment-naive patients [33] [34] [35] (Kwo et al., 2010) (Poordad et al., 2011) (Jacobson et al., 2011), there still existed some populations that could hardly see much progresses with the new treatment and the DAAs also caused additional side effects such as anemia, dysgeusia for BOC, rash and anorectal symptoms for TVR [36] (González-Moreno et al., 2013). Therefore, more advanced treatments remained highly demanded.

Under this circumstance, the development of second-generation NS3/4A protease inhibitors, simeprevir (SMV) included, came into occurrence. Different NS3/4 inhibitors such as SMV, Grazaoprevir (ZGR), Paritaprevir (PTV), Asunaprevir (ASN), Voxileprevir (VOX), and Glecaprevir (GLC) were combined with PEG-IFN and RBV to be used as triple therapies [37] [38] [39] [40] (Jacob- 
son et al., 2014) (Manns et al., 2014) (Summa et al., 2012) (Muir et al., 2015). Each of them also achieved a certain degree of progress on their SVR rates based on various genotypes, but limitations and side effects from the second-generation DAA treatments were still not minimized to an acceptable level.

Later, other classes of DAA such as nucleotide NS5B polymerase inhibitors including sofosbuvir (SOF) were added to the combination therapy, offering advantages such as shorter treatment course and minor side effects. However, treatment-intolerant problems of patients with decompensated cirrhosis and significant medical or psychiatric comorbidities remain unsolved [41] (Lawitz et al., 2013).

Finally, IFN-free DAA combination therapy has been developed, leading to a superiority in various aspects, including elevated SVR rate, minor side effects, shortened treatment courses, improved cost effectiveness, and most importantly, broader applications on populations. With these noticeable improvements made by IFN-free DAAs, it is crucial to be aware that many aspects of IFN-free DAAs remain unknown and further studies and experiments are required.

In order to analyze the impact of developing effective treatment against $\mathrm{HCV}$ in China, we did research about one of the most advanced techniques in treating $\mathrm{HCV}$, which is now widely used in industrialized countries and may also aid treatment of HCV patients in China. By analyzing impact of DAA treatment in Europe and Australia, we aim to critically evaluate the potential impact on Chinese patients and try to highlight strategies that have proven to be successful elsewhere and could potentially be employed also in China.

\section{Comparison with Different Countries}

\subsection{Australia}

Hepatitis C is one of the most common viral infections in Australia [42] (Blumer et al., 2003). Approximately 230,470 Australian citizens are living with chronic hepatitis C, which is $0.96 \%$ of the total Australian population ( 24 million), in 2016 [43] Kirby Institute, 2014). And among the six main GT of HCV, GT 1a together with $1 \mathrm{~b}$ and $3 \mathrm{a}$ are the most common genotypes in Australia, with a prevalence rate of 54\% and 37\% respectively [44] (McCaw R. et al., 2010). And unsafe injecting drug use has been the most common reason for newly acquired $\mathrm{HCV}$ infection, with a percentage of $80 \%$ among all causes of $\mathrm{HCV}$ infection. Other major factors that lead to the infection of HCV in Australia include inappropriate medical procedures and other forms of blood-to-blood contact such as unsterile tattooing [45] (Hepatitis C Virus Infection Consensus Statement Working Group, 2017). Although the hepatitis C problem is severe in Australia, its hepatitis $\mathrm{C}$ treatment policy is one of the most progressive and arguably effective in the world, highly accessible and effective.

As a result of the significant prevalence in Australia, Australian government establishes an elaborate series of health care procedures to target at HCV. Since 1990, an acute test for hepatitis $\mathrm{C}$ diagnosis has been available, whose principle is 
basically measuring the antibodies induced by HCV. Nowadays, to confirm the infection of $\mathrm{HCV}$ and prescribe treatments, citizens are required to undergo several tests including blood test, HCV genotype confirmation test, cirrhosis assessment, previously taken HCV treatment confirmation, health care history discussion and currently taking drug confirmation [46] (hepatitisaustralia.com, 2015). After taking all these examinations, Australian citizens can then derive prescriptions of DAAs, the most advanced hepatitis $C$ treatment worldwide, from doctors, general practitioners (GPs), or specialists such as gastroenterologists, hepatologists or infectious diseases physicians. After that patients will undergo a course of treatment ranging between 8 and 24 weeks followed by ideal treatments or extra treatments depending on individual's variant need.

Since 1 January 2017, the HCV medicine used in Australia has been DAAs, whose SVR rate is over $90 \%$ and mainly including Daklinza (daclatasvir), Harvoni (sofosbuvir + ledipasvir), Ibavyr (ribavirin), Sovaldi (sofosbuvir), Viekira Pak (paritaprevir + ritonavir + ombitasvir + dasabuvir), Viekira Pak RBV (paritaprevir + ritonavir + ombitasvir + dasabuvir + ribavirin) and Zepatier (grazoprevir + elbasvir) and whether these DAAs will be used in combination with IFNs depends on different circumstances [46] (hepatitisaustralia.com, 2015). The advantages of DAAs over pre-DAA era treatments, which has been demonstrated in the introduction, are that DAAs improve Australian citizens' life quality, diminish HCV infectivity and lower the risk of liver failure, hepatocellular carcinoma (HCC) as well as mortality reduction [45] (Hepatitis C Virus Infection Consensus Statement Working Group, 2017).

The cost of these new medicines, DAAs, is currently 38.30 Australian dollars for general patients and 6.20 Australian dollars for concessional patients, affordable to every Australian citizen [46] (hepatitisaustralia.com, 2015). The reason for the low price is that the Australian government has subsidised HCV treatment with over 1 billion dollars for the whole population, which is $0.059 \%$ of its 2016 GDP (1.67 trillion dollars).

To conclude, Australian government holds high regard on the HCV infection issue. It costs 1 billion dollars on HCV treatments and provides broad accesses for Australian citizens to the treatment. As a matter of fact, Australia is one of the first countries in the world to publicly subsidize therapy of a certain disease for their entire population, regardless the patient's condition [47] (Adam, 2015), which means that even people in prison or are currently injecting drugs are accessible to the new treatment. Although there still exist certain difficulties like IFN-free DAAs targeting GT 5 and 6 remain unavailable, the Australian government are now working actively on this problem and will come up with a solution as soon as possible [46] (hepatitisaustralia.com, 2015). With such considerable effort, it is predicted that eradication of HCV will be accomplished in Australia in 2026, according to the Australian researchers [48] (Lucy, 2017). And Australia is currently the most successful example of government-regulated HCV treatment for the entire community. 


\subsection{Europe}

HCV also remains highly prevalent in Europe and a variety of treatment options are now becoming available to treat HCV in European countries. In the past 15 years, worldwide efficacy of the therapeutic options for HCV has dramatically improved [49] (European Association for the Study of the Liver, 2012). In Europe, some developed countries such as Britain and Italy adopted treatments that are benefiting the infected people and promoting the process of developing effective drugs.

In 1990, globally, just $10 \%$ among patients had been treated with interferon monotherapy. The rate has been significantly increased in these days with the help of advanced technology. The cure rate, measured by SVR has been improved up to $80 \%$ in some particular GT with current treatment so called standard of care (SOC) and are desired to reach up to $90 \%$ or more with employment of DAA [50] (Poordad et al., 2012). Nowadays, for any kind of treatment, the time for therapy will be different. By looking at the response to drugs by virus, patients who rapidly clear virus from their body will be eligible to receive a shorter duration of therapy. On the other hand, patients who has much more severe problems which caused by virus infection will be provided an extended duration of therapy [48] (Lucy, 2017).

In European countries, there is a large proportion of chronic hepatitis $\mathrm{C}$ $(\mathrm{CHC})$ infected people, approximately $1 \%$, who are most age 60 years and older. Many of these patients have progressed in their disease and are now presenting with severe liver problems. Almost 80,000 are cirrhotic of which at least 3000 suffer from liver decompensation. Moreover, infection due to transplant is about 500 per year and end with death caused by HCV is about 10,000 per year [51] (Vigana et al., 2017). DAAs are now widely used across different European countries and show remarkable treatment successes.

In Italy, according to The Italian Medications Agency (AIFA), merely patients with very severe problems with liver can be treated by DAAs. Mostly, patients will take drugs if they have CHC, HCV recurrence after liver transplant of solid organ despite of liver, or liver disease with extra-hepatic manifestations. Furthermore, the price of DAA was still negotiated with price/volume agreement then it is desirable to have the full treatment with nearly $6000-10,000$ Euros. DAA is expected to be used in treating HCV in long term [52] (Sciences et al., 2012). In the future improvement on DAA, there will be less RBV involved in the combination treatment and the quality and quantity of SVR will be the dominant part in the therapy. Fortunately, DAAs are not only highly effective but also show few sides effects increasing the comfort for patients to follow the therapy. With the help of the new advanced version of therapy, HCV will have the potential to be eradicated from the world [51] (Vigana et al., 2017).

In Scotland, there are approximately 37,000 people infected or undiagnosed with HCV. It is the goal to eradicate HCV in Scotland by 2030. However, this ambitious goal may be hard to achieve. The charity Waverley Care said that Scotland is still having the highest prevalence of the virus in the UK. 1800 new 
cases are diagnosed every year [50] (Lucy, 2017). In Scotland, failed treatment of HCV will not cost the patient the money for drugs. The money will be returned to patient. The manufacture, Janssen, will pay money for pre-treatment of the blood test for patient to predict whether the treatment will be useful or not for patients before they take the therapy.

In Europe, Antiviral drugs sales such as sale of $\mathrm{HIV}, \mathrm{HBV}$ and $\mathrm{HCV}$ products were 6.4 billion dollars for the second quarter of 2017 compared to 7.1 billion dollars for the same time period in 2016 [53] (Hep. News, 2016). Drugs for HCV treatment, which involved Harvoni, Sovaldi, and Epclusa were 2.9 billion dollars compared to 4 billion dollars for the same time in 2016. The declination of price within one year is due to lower sales of Harvoni and Sovaldi in markets [53] (Hep. News, 2016).

After combining several results that collected in Europe about prices of new effective drugs, duration of therapy, numbers of people that has been infected and expectations of a desirable situation about treating HCV, we can say that use of DAAs for treating HCV has helped European patients significantly.

\subsection{China}

It is estimated that there are approximately 13 million HCV infected persons in China [54] (Sievert et al., 2011). According to the China Ministry of Health Annual Reports, reported cases of CHC are still increasing steadily since 2003 [55] (China Center for Disease Control and Prevention, 2012). The prevalence is $1.8 \%$ - 3.7\% [56] (Micallef et al., 2006) (see Table 1). In addition to intravenous drug use (IVDU) with contaminated needles that represent the most dominant way of HCV transmission in developed countries, risk factors in China also include transfusions of contaminated blood products and unsterilized syringe [57] (Duan et al., 2014)

Among the infected population, only $25 \%$ can be cured while $75 \%$ will finally progress to $\mathrm{CHC}$. CHC patients are likely to undergo fibrosis progress, decompensated cirrhosis, and hepatocellular carcinoma. This further leads to great economic and health burden for patients and society [58] (Chen et al., 2002). In fact, early treatment is very important to prevent the progression of hepatitis $\mathrm{C}$ to cirrhosis and hepatocellular carcinoma [59] (Feng et al., 2011). However, because of the unspecific symptoms of $\mathrm{HC}$ and the low awareness of Chinese people, many hepatitis $\mathrm{C}$ patients miss the opportunity to get suitable treatment in time. According to a survey, when asked about HCV transmissions, detection measures, etiology, treatments, and preventions, Chinese people know little about them [58] (Chen et al., 2002). Most of hepatitis C patients are almost remain untreated [57] (Duan et al., 2014). This is obviously one of the main obstacles in hepatitis $\mathrm{C}$ management in China.

Six of seven GTs of HCV have been found in China. GT $1 \mathrm{~b}$ and $2 \mathrm{a}$ are two main subtypes that account for about 63\% and 17\% respectively [60] (Yu et al., 2017). Different GTs of HCV shows various treatment effects. Patients with GT 
Table 1. The comparison of scenario in China, Australia and Europe.

\begin{tabular}{|c|c|c|c|}
\hline & Australia & China & Europe \\
\hline HC population & 0.24 million & 13 million & 7.6 million \\
\hline HCV prevalence & $\begin{array}{c}0.96 \% \text { (for the entire } \\
\text { population) }\end{array}$ & $1.8 \%-3.7 \%$ & Approximately $1.0 \%$ \\
\hline Main GT & $1 \mathrm{a}$ and $1 \mathrm{~b}$ ( $54 \%$ prevalence) & $63 \% 1 \mathrm{~b}$ & $68 \% 1 \mathrm{~b}$ \\
\hline Midili 1 & 3a (37\% prevalence) & $17 \% 2 \mathrm{~b}$ & $30 \% 2 a$ \\
\hline Treatment & DAAs & $\begin{array}{c}\text { PEG-IFN/IFN + RBV } \\
\text { DCV + ASN }\end{array}$ & DAAs \\
\hline Access & Hospitals, specialists & Hospital & Hospitals, specialists \\
\hline Cost/per course $(\$)$ & $\begin{array}{l}38.30 \text { for general patients } \\
6.20 \text { for concessional patients }\end{array}$ & $\begin{array}{c}\text { PEG-IFN + } \\
\text { RBV-4976 } \\
\text { DCV + ASN-8560 }\end{array}$ & $7014-11690$ \\
\hline $\begin{array}{c}\text { Income per capita } \\
(\$)\end{array}$ & 55,914 & 7442 & 28,900 \\
\hline
\end{tabular}

For European countries, the situation is that by looking at its even GDP, it is relatively affordable comparing to that of China. The treatment is meanly PEG + IFN alpha + Simeprevir with or without RBN, depend on the condition of patients. The population of patient is also much smaller than that of China.

2 and 3 can achieve high SVR of 70\% - 80\%, yet patients with GT 1 or 4 achieve lower SVR of 40\% - 50\% [61] [62] [63] [64] (Zhao et al., 2008) (Bi et al., 2015) (Omata et al., 2012) (Ghany et al., 2011). With the development of DAA and its combinational therapy, the SVR can reach more than $90 \%$ in almost all GTs and stages of hepatitis C [65] [66] (Feeney et al., 2014) (Pawlotsky, 2014).

After China Food and Drug Administration (CFDA) approved two DAAs in April 2017, the treatment for adults with chronic hepatitis C GT 1b (without cirrhosis or decompensated cirrhosis) - DCV tablets combined with ASV soft capsules had officially launched in China Market in July 10th. Until July 25th, the two drugs had been delivered to 121 hospitals, 548 pharmacies around the country, including the Direct to Patient (DTP) pharmacy, a professional pharmacy. This combination therapy is the first and only all-oral DAA in China now. It takes $\$ 8560$ for one 24 weeks treatment course. Currently, the standard treatment for HC patients infected with GT 1 is still PEG-IFN or IFN plus RBV for 48 weeks [67] (Chinese Society of Hepatology, 2015). The average cost for the method was $\$ 4976$. Although most inpatients have health insurance to cover around $60 \%$ of the expense, nearly $50 \%$ of the outpatient cases are not covered by insurance. So if HC patients choose PEG-IFN plus RBV treatment, they have chance to be funded by the government and pay $\$ 1990$. Until now, DCV combine with ASV treatment has not been included on the list of diseases that can get health insurance, so hepatitis $C$ patients need to pay $\$ 8560$ on their own. In 2015 , the GDP per capita in China is $\$ 7442$. Considering the vast inequalities in wealth between the rich and poor, this figure cannot represent the economic ability of the hepatitis C patients. In 2016, urban disposable income per capita is $\$ 4978$, while in rural areas the number is $\$ 1831$. Both the dominant PEG-IFN treatment and DCV plus ASN treatment are financial burdens for most Chinese patients. DAA is an expensive medicine but things are much better now for 
Chinese patients because they can get relatively economical and safe treatment in their own countries. In the past, they needed to pay about $\$ 84,000$ for a single 12 -week course of sofosbuvir made from USA or buy generic drugs from India. The price is $\$ 900$, which is much lower, but there is a risk of getting fake medicine.

The price could be much lower. A research group predicted the minimum cost of HCV DAA treatment by compare to HIV antiretroviral (ARV) regiment [68] (Hill et al., 2014). Based on molecular weight, chemical structure, class, and dose, the cost of atazanavir is similar to DCV [68] (Hill et al., 2014). The estimated costs for a 12-week course of DCV treatment were \$10 - \$30 [68] (Hill et al., 2014). In China, the treatment of DCV combined with ASV for GT 1 patients lasts for 24-week. The number should be doubled to $\$ 20-\$ 60$. Since the cost of ASV is approximately 10 times less than the cost of DCV, the price of ASV is not considered. Roughly, the least cost of this new combinational DAA treatment is $\$ 20$.

\subsection{Comprehensive Analysis}

Through studying HCV-treatment conditions in Australia and Europe, a basic knowledge of how they establish DAAs to broader spectrum of their population has been derived. In Australia, the government spent 1 billion buying new medicines for their entire population and made the most effective therapies available to every Australian citizen. In Europe, the costs for the new, very expensive drugs are covered by the insurance thus more accessible to them. Scotland even returns the cost if the drug is not effective and Britain provides alternative treatments for patients. However, all these effective methods for public HCV treatment are not suitable to China. Firstly, it is not practical for Chinese government to buy treatments for the entire population as Australia did, since the total population of China is too large and the infection rate can reach up to $1.8 \%$ - $3.7 \%$. Secondly, the GDP per capita in China is $\$ 7442$, indicating that the majority of Chinese population is not affordable to the DAA treatment (\$8560). The wealth gap is also considerably big in China. As a result, it will be impossible for most Chinese patients to buy the new drugs on their own like Europeans do.

Although the Chinese government cannot follow the exactly same path Australia and Europe do, their cases do provide China with referential experience, for instance, the introduction of DAAs into China.

Based on the situation in China, the Chinese government has developed a unique pathway to allow Chinese population become gradually accessible to the latest treatments. After negotiation, Chinese government reached an agreement with a transnational company and made DAAs available to Chinese citizens in July 10, 2017, which leads to a series of positive impacts on China. Before 2017 even people who are affordable to the new drugs are not able to access them, at present, though some people still cannot afford the current price, at least a portion of Chinese citizens can be treated with higher cure rate and minor side ef- 
fects, contributing to the overall cure rate in China as well as limited new infections with HCV. The presence of DAAs also increases citizen's confidence to the treatment of $\mathrm{HCV}$ and provides the economically-limited $\mathrm{HCV}$ patients with hope for future access to the better drug, since they can expect that the government will develop related health insurance or further reduce the cost of the drug. In addition, Chinese HCV drug development will be facilitated due to the cooperation with transnational company to produce DAAs.

To conclude, DAAs, the new HCV treatment, has not only provided more preferable HCV therapies, improving the cure rate of HCV in China, but also increased citizens' confidence of the treatment and offered new imputes for Chinese HCV drug invention. As for the limitation of the popularization of the new treatment, the Chinese government is currently striving for fixing solutions and the future improvement is what we can look forward to.

\section{Discussion}

DAAs can efficiently cure HCV in virtually all patient populations. It has the similar safety and efficacy in patients with or without compensated cirrhosis [69] (Kao et al., 2016). However, the treatment could not be used on patients with cirrhosis or decompensated cirrhosis in China or be used on children. Further clinical trials need to be done. The two major problems now are low awareness of HCV in the Chinese population and the cost of DAAs. As for the low awareness, the Chinese Health Promotion and Education Association sponsored "Hepatitis C Education Program", which aims to educate people and provide advice for HC patients. Within 10 months, the program is expected to raise awareness among Chinese people. This would not only prevent more people from getting hepatitis $\mathrm{C}$, but also encourage people to do physical examination when they have a risk of infecting HCV.

Since the most cost part of a drug is patent, the cost of DAAs can be much lower if patent can be circumvented. Some domestic pharmaceutical manufacturers had already produced some drugs which they have independent intellectual property right on, including danoprevir (ASC08), yimitasvir, ravidasvir. These are also some pharmaceutical companies waiting for the DAAs invented by foreign countries to lose the patent protection. After that, they will have the chance to produce generic DAAs in China. The new DAAs are produced by transnational corporations, so their price might be higher. In a few years, more and more DAAs are expected to come into China market with the development of many domestic pharmaceutical manufacturers. The domestic DAAs will likely be cheaper. As the diagnosis rate improves, the demand of DAAs will increase dramatically, the competition between pharmaceutical manufacturers will be more intense. Under such circumstances, the price of DAAs will be much lower than what it is now.

There are two advantages of China Market. One is cheap labor, another is potential purchasing ability. Some Chinese pharmaceutical companies take use of 
these two and produce cheaper DAAs. After the new DAAs made by Chinese company came into market soon, these drugs can also expand out sea market in developed countries, where DAAs is expensive. Furthermore, China exports large amount of unprocessed drug materials to some countries like India every year. When other pharmaceutical companies can produce generic DAAs, they can make cheaper ones than Indian generic DAAs. At that time, China can mainly export generic DAAs instead of raw materials.

The situation of curative treatment for hepatitis $\mathrm{C}$ in different countries is quite different. Italy will merely use the advanced treatment of HCV to patients who have severe symptoms and tough liver problems. High-income countries like Australia are able to negotiate with pharmaceutical companies with lower price and their citizens can be fully covered by national reimbursement. Since the hepatitis C population in Australia is far less than that in China, the Australian government invested 1 billion to buy DAAs at one time and solved the problem of drug shortage efficiently. Most low-income countries like India are included in the voluntary license agreements by pharmaceutical companies. China cannot take any of these approaches. The population of China is more than 1.4 billion so the government certainly could not buy drugs for people. As an upper-middle income country, there is also no reason to be helped by volunteers. A practical approach for China is to put DAAs treatment into the list of Medicaid as soon as possible.

An effective way for China is to invent their own DAAs but drug developing usually takes 10 - 15 years until a product is on the market. This is too late for millions of patients who are suffering from $\mathrm{CHC}$ nowadays. For the future development of drugs that can cure $\mathrm{CHC}$, China needs to play a bigger role in drug intervention to keep population away from suffering the pain of $\mathrm{HCV}$.

\section{Conflicts of Interest}

The authors declare no conflicts of interest regarding the publication of this paper.

\section{References}

[1] Burstow, N.J., Mohamed, Z., Gomaa, A.I., Sonderup, M.W., Cook, N.A., Waked, I., et al. (2017) Hepatitis C Treatment: Where Are We Now? International Journal of General Medicine, 10, 39-52. https://doi.org/10.2147/IJGM.S127689

[2] World Health Organization (2017) Global Hepatitis Report. Geneva.

[3] Tyagi, I. and Koirala, J. (2017) Hepatitis C. Annals of Internal Medicine, 125, 658-668.

[4] Ray, S.C., Bailey, J.R. and Thomas, D.L. (2013) Hepatitis C, Chapter 27. In: Knipe, D.M. and Howley, P.M., Eds., Fields Virology, Lippincott Williams \& Wilkins, Philadelphia, PA, 795-824.

[5] Seeff, L.B. (2004) Natural History of Hepatitis C. Hepatology, 51, 63-75.

[6] Hajarizadeh, B., Grebely, J. and Dore, G.J. (2013) Epidemiology and Natural History of HCV Infection. Nature Reviews Gastroenterology \& Hepatology, 10, 553-562. https://doi.org/10.1038/nrgastro.2013.107 
[7] Koziel, M.J. and Peters, M.G. (2007) Viral Hepatitis in HIV Infection. New England Journal of Medicine, 356, 1445-1454. https://doi.org/10.1056/NEJMra065142

[8] Miao, Z., Xie, Z., Miao, J., Ran, J., Feng, Y. and Xia, X. (2017) Regulated Entry of Hepatitis C Virus into Hepatocytes. Viruses, 9, 100. https://doi.org/10.3390/v9050100

[9] Murphy, K. and Casey, W. (2016) Janeway's Immunobiology. Garland Science/Taylor \& Francis Group, LLC Print, New York, NY.

[10] Simmonds, P., Irvine, B., Yap, P.L., Kolberg, J., Chan, S.-W., Cha, T.-A., Beall, E., Urdea, M.S., Holmes, E.C. and Mcomish, F. (1993) Classification of Hepatitis C Virus into Six Major Genotypes and a Series of Subtypes by Phylogenetic Analysis of the NS-5 Region. Journal of General Virology, 74, 2391-2399. https://doi.org/10.1099/0022-1317-74-11-2391

[11] De, A.M., Ravera, R., Gioia, D., Gariglio, M. and Landolfo, S. (2002) The Interferon System: An Overview. European Journal of Paediatric Neurology, A41-A46, A55-A58.

[12] Parkin, J. and Cohen, B. (2001) An Overview of the Immune System. The Lancet, 357, 1777-1789. https://doi.org/10.1016/S0140-6736(00)04904-7

[13] Fensterl, V. and Sen, G.C. (2009) Interferons and Viral Infections. Biofactors, 35, 14-20. https://doi.org/10.1002/biof.6

[14] De Veer, M.J., Holko, M., Frevel, M., Walker, E., Der, S., Paranjape, J.M., Silverman, R.H. and Williams, B.R. (2001) Functional Classification of Interferon-Stimulated Genes Identified Using Microarrays. Journal of Leukocyte Biology, 69, 912-920.

[15] Moiseeva, O., Mallette, F.A., Mukhopadhyay, U.K., Moores, A. and Ferbeyre, G. (2006) DNA Damage Signaling and p53-Dependent Senescence after Prolonged $\beta$-Interferon Stimulation. Molecular Biology of the Cell, 17, 1583-1592. https://doi.org/10.1091/mbc.e05-09-0858

[16] Anonymous (1997) National Institutes of Health Consensus Development Conference Panel Statement: Management of Hepatitis C. Hepatology, 26, 2 S. https://doi.org/10.1002/hep.510260701

[17] Carithers Jr., R.L. and Emerson, S.S. (1997) Therapy of Hepatitis C: Meta-Analysis of Interferon Alfa-2b Trials. Hepatology, 26, 83S-88S.

[18] McHutchison, J.G., Gordon, S.C., Schiff, E.R., et al. (1998) Interferon Alfa-2b Alone or in Combination with Ribavirin as Initial Treatment for Chronic Hepatitis C. Hepatitis Interventional Therapy Group. The New England Journal of Medicine, 339, 1485-1492. https://doi.org/10.1056/NEJM199811193392101

[19] European Association for Study of Liver (2011) EASL Clinical Practice Guidelines: Management of Hepatitis C Virus Infection. Journal of Hepatology, 55, 245-264. https://doi.org/10.1016/j.jhep.2011.02.023

[20] Di Bisceglie, A.M. and Hoofnagle, J.H. (2002) Optimal Therapy of Hepatitis C. Hepatology, 36, S121-S127.

[21] European Association for Study of Liver (2015) EASL Recommendations on Treatment of Hepatitis C. Journal of Hepatology, 63, 199-236. https://doi.org/10.1016/j.jhep.2015.03.025

[22] Antaki, N., Craxi, A., Kamal, S., Moucari, R., Van der Merwe, S., Haffar, S., et al. (2010) The Neglected Hepatitis C Virus Genotypes 4, 5 and 6: An International Consensus Report. Liver International Official Journal of the International Association for the Study of the Liver, 30, 342-355. https://doi.org/10.1111/j.1478-3231.2009.02188.x

[23] Fried, M.W., Shiffman, M.L., Reddy, K.R., Smith, C., Marinos, G., Jr., G.F., et al. (2003) Peginterferon Alfa-2a plus Ribavirin for Chronic Hepatitis C Virus Infection. 
The New England Journal of Medicine, 351, 975-982.

[24] The American Society of Health-System Pharmacists (2016) Ribavirin.

[25] Ortega-Prieto, A.M., Sheldon, J., Grande-Pérez, A., Tejero, H., Gregori, J., Quer, J., Esteban, J.I., Domingo, E. and Perales, C. (2013) Extinction of Hepatitis C Virus by Ribavirin in Hepatoma Cells Involves Lethal Mutagenesis. PLoS ONE, 8, e71039. https://doi.org/10.1371/journal.pone.0071039

[26] Crotty, S., Cameron, C. and Andino, R. (2002) Ribavirin's Antiviral Mechanism of Action: Lethal Mutagenesis? Journal of Molecular Medicine, 80, 86-95. https://doi.org/10.1007/s00109-001-0308-0

[27] Fischer, J. and Ganellin, C.R. (2006) Analogue-Based Drug Discovery. John Wiley \& Sons, Hoboken, 504. https://doi.org/10.1002/3527608001

[28] Snell, N.J. (2001) Ribavirin-Current Status of a Broad Spectrum Antiviral Agent. Expert Opinion on Pharmacotherapy, 2, 1317-1324.

https://doi.org/10.1517/14656566.2.8.1317

[29] Hézode, C., Fontaine, H., Dorival, C., et al. (2013) Triple Therapy in TreatmentExperienced Patients with HCV-Cirrhosis in a Multicenter Cohort of the French Early Access Programme (ANRS CO20-CUPIC) NCT01514890. Journal of Hepatology, 59, 434-441. https://doi.org/10.1016/j.jhep.2013.04.035

[30] Bruchfeld, A., Lindahl, K., Ståhle, L., Söderberg, M. and Schvarcz, R. (2003) Interferon and Ribavirin Treatment in Patients with Hepatitis C-Associated Renal Disease and Renal Insufficiency. Nephrology, Dialysis, Transplantation: Official Publication of the European Dialysis and Transplant Association-European Renal Association, 18, 1573-1580. https://doi.org/10.1093/ndt/gfg209

[31] Ward, R.P. and Kugelmas, M. (2005) Using Pegylated Interferon and Ribavirin to Treat Patients with Chronic Hepatitis C. American Family Physician, 72, 655-662.

[32] Schinazi, R., Halfon, P., Marcellin, P. and Asselah, T. (2014) HCV Direct-Acting Antiviral Agents: The Best Interferon-Free Combinations. Liver International Official Journal of the International Association for the Study of the Liver, 34, 69.

[33] Kwo, P.Y., Lawitz, E.J., McCone, J., et al. (2010) Efficacy of Boceprevir, an NS3 Protease Inhibitor, in Combination with Peginterferon Alfa-2b and Ribavirin in Treatment-Naïve Patients with Genotype 1 Hepatitis C Infection (SPRINT-1): An Open-Label, Randomized, Multicenter Phase 2 Trial. The Lancet, 376, 705-716. https://doi.org/10.1016/S0140-6736(10)60934-8

[34] Poordad, F., McCone, J., Bacon, B.R., et al. (2011) Boceprevir for Untreated Chronic HCV Genotype 1 Infection. The New England Journal of Medicine, 364, 1195-1206. https://doi.org/10.1056/NEJMoa1010494

[35] Jacobson, I.M., McHutchison, J.G., Dusheiko, G., et al. (2011) Telaprevir for Previously Untreated Chronic Hepatitis C Virus Infection. The New England Journal of Medicine, 364, 2405-2416. https://doi.org/10.1056/NEJMoa1012912

[36] González-Moreno, J. and Payeras-Cifre, A. (2013) Hepatitis C Virus Infection: Looking for Interferon Free Regimens. The Scientific World Journal, 2013, Article ID: 825375. https://doi.org/10.1155/2013/825375

[37] Jacobson, I.M., Dore, G.J., Foster, G.R., et al. (2014) Simeprevir with Pegylated Interferon Alfa 2a plus Ribavirin in Treatment-Naive Patients with Chronic Hepatitis C Virus Genotype 1 Infection (QUEST-1): A Phase 3, Randomised, Double-Blind, Placebo-Controlled Trial. The Lancet, 384, 403-413. https://doi.org/10.1016/S0140-6736(14)60494-3

[38] Manns, M., Marcellin, P., Poordad, F., et al. (2014) Simeprevir with Pegylated Interferon Alfa $2 \mathrm{a}$ or $2 \mathrm{~b}$ plus Ribavirin in Treatment-Naive Patients with Chronic 
Hepatitis C Virus Genotype 1 Infection (QUEST-2): A Randomised, Double-Blind, Placebo-Controlled Phase 3 Trial. The Lancet, 384, 414-426. https://doi.org/10.1016/S0140-6736(14)60538-9

[39] Summa, V., Ludmerer, S.W., McCauley, J.A., et al. (2012) MK-5172, a Selective Inhibitor of Hepatitis C Virus NS3/4a Protease with Broad Activity across Genotypes and Resistant Variants. Antimicrobial Agents and Chemotherapy, 56, 4161-4167. https://doi.org/10.1128/AAC.00324-12

[40] Muir, A.J., Poordad, F., Lalezari, J., Everson, G., Dore, G.J., Herring, R., et al. (2015) Daclatasvir in Combination with Asunaprevir and Beclabuvir for Hepatitis C Virus Genotype 1 Infection with Compensated Cirrhosis. JAMA, 313, 1736. https://doi.org/10.1001/jama.2015.3868

[41] Lawitz, E., Poordad, F., Brainard, D.M., et al. (2013) Sofosbuvir in Combination with PegIFN and Ribavirin for 12 Weeks Provides High SVR Rates in HCV-Infected Genotype 2 or 3 Treatment-Experienced Patients with and without Compensated Cirrhosis: Results from the LONESTAR-2 Study. Hepatology, 58, 1380A.

[42] Blumer, C., Roche, P., Spencer, J., Lin, M., Milton, A., Bunn, C., et al. (2003) Australia's Notifiable Diseases Status, 2001: Annual Report of the National Notifiable Diseases Surveillance System. Communicable Diseases Intelligence, 27, 1-78.

[43] Kirby Institute (2014) HIV, Viral Hepatitis and Sexually Transmissible Infections in Australia: Annual Surveillance Report 2013.

[44] Mccaw, R., Moaven, L., Locarnini, S.A. and Bowden, D.S. (2010) Hepatitis C Virus Genotypes in Australia. Journal of Viral Hepatitis, 4, 351-357. https://doi.org/10.1046/j.1365-2893.1997.00060.x

[45] Hepatitis C Virus Infection Consensus Statement Working Group (2017) Australian Recommendations for the Management of Hepatitis C Virus Infection: A Consensus Statement. Gastroenterological Society of Australia, Melbourne.

[46] (2015) About Hepatitis C. http://www.hepatitisaustralia.com/hepatitis-c-facts/about-hep-c

[47] Adam, G. (2015) Turnbull Government to Spend 1 Billion on Hepatitis C "Miracle Cures" for All.

[48] Lucy, C. (2017) Hepatitis C Will Be Eradicated in Australia by 2026, Researchers Predict.

[49] European Association for Study of Liver (2012) Easl Clinical Practice Guidelines: Management of Chronic Hepatitis B Virus Infection. Journal of Hepatology, 57, 167-185. https://doi.org/10.1016/j.jhep.2012.02.010

[50] Poordad, F., Lawitz, E., Kowdley, K., et al. (2012) 12-Week Interferon-Free Regimen of ABT-450/R+ABT-333+ Ribavirin Achieved SVR12 in More than $90 \%$ of Treatment-Naive HCV GT-1-Infected Subjects and 47\% of Previous Non-Responders. Journal of Hepatology, 56, S549-S550.

[51] Vigan, A.M., Carlo, F.P., Antonio, C., Alessio, A., Alfredo, A., Pietro, A., et al. (2017) Treatment of Hepatitis C Virus Infection in Italy: A Consensus Report from an Expert Panel. Digestive and Liver Disease, 49, 731-741. https://doi.org/10.1016/j.dld.2017.03.027

[52] Sciences, G. and Million, W. (2012) Gilead Sciences Announces Second Quarter 2012 Financial Results. Gilead Sciences Inc., Foster City.

[53] (2016) Europe Approves AbbVie's New Hepatitis C Treatment. Hepatitis News.

[54] Sievert, W., Altraif, I., Razavi, H.A., Abdo, A., Ahmed, E.A., Alomair, A., et al. (2011) A Systematic Review of Hepatitis C Virus Epidemiology in Asia, Australia and Egypt. Liver International, 31, 61-80. 
https://doi.org/10.1111/j.1478-3231.2011.02540.x

[55] China Center for Disease Control and Prevention, Ministry of Health (2003-2012) National Official Infectious Disease Reports. http://www.china.cdc.cn/tjsj/fdcrbbg/

[56] Micallef, J.M., Kaldor, J.M. and Dore, G.J. (2006) Spontaneous Viral Clearance Following Acute Hepatitis C Infection: A Systematic Review of Longitudinal Studies. Journal of Viral Hepatitis, 13, 34. https://doi.org/10.1111/j.1365-2893.2005.00651.x

[57] Duan, Z., Jia, J.D., Hou, J., Lou, L., Tobias, H., Xu, X.Y., et al. (2014) Current Challenges and the Management of Chronic Hepatitis C in Mainland China. Journal of Clinical Gastroenterology, 48, 679-686.

https://doi.org/10.1097/MCG.0000000000000109

[58] Chen, Y.D., Liu, M.Y., Yu, W.L., Li, J.Q., Peng, M., Dai, Q., et al. (2002) Hepatitis C Virus Infections and GTs in China. Hepatobiliary \& Pancreatic Diseases International: HBPD INT, 1, 194-201.

[59] Bo, F., Jin, Z. and Lai, W. (2011) Inadequate Awareness of Hepatitis C among Nonspecialist Physicians in China. Advances in Medical Education \& Practice, 2, 209.

[60] Yu, Z., Chen, L.M. and Miao, H. (2017) Hepatitis C Virus in Mainland China with an Emphasis on Genotype and Subtype Distribution. Virology Journal, 14, 41. https://doi.org/10.1186/s12985-017-0710-Z

[61] Zhao, S., Liu, E., Yu, H., Yang, H., Xun, M., Xue, X., Song, J., Xu, K. and Chu, Y. (2008) Comparison of Peginterferon and Interferon in Treating Chinese Patients with Chronic Hepatitis C. Hepatogastroenterology, 55, 1047-1054.

[62] Bi, M.R., Kang, L., Zhang, K. and Yang, B.S. (2015) Clinical Significance of Different HCV GTs and Discussion about Treatment Effect of Interferin. Chinese Journal of Frontier Medical Science, 7, 76-79.

[63] Omata, M., Kanda, T., Yu, M.L., Yokosuka, O., Lim, S.G., Jafri, W., Tateishi, R., Hamid, S.S., Chuang, W.L., Chutaputti, A., et al. (2012) APASL Consensus Statements and Management Algorithms for Hepatitis C Virus Infection. Hepatology International, 6, 409-435. https://doi.org/10.1007/s12072-012-9342-y

[64] Ghany, M.G., Nelson, D.R., Strader, D.B., Thomas, D.L. and Seeff, L.B. (2011) An Update on Treatment of GT 1 Chronic Hepatitis C Virus Infection: 2011 Practice Guideline by the American Association for the Study of Liver Diseases. Hepatology, 54, 1433-1444. https://doi.org/10.1002/hep.24641

[65] Feeney, E.R. and Chung, R.T. (2014) Antiviral Treatment of Hepatitis C. BMJ, 348, g3308. https://doi.org/10.1136/bmj.g3308

[66] Pawlotsky, J.M. (2014) New Hepatitis C Therapies: The Toolbox, Strategies, and Challenges. Gastroenterology, 146, 1176-1192. https://doi.org/10.1053/j.gastro.2014.03.003

[67] Chinese Society of Hepatology (2015) The Guidelines of Prevention and Treatment for Chronic Hepatitis C. Chinese Hepatology, 33, 192-194.

[68] Hill, A., Khoo, S., Fortunak, J., Simmons, B. and Ford, N. (2014) Editor's Choice: Minimum Costs for Producing Hepatitis C Direct-Acting Antivirals for Use in Large-Scale Treatment Access Programs in Developing Countries. Clinical Infectious Diseases. An Official Publication of the Infectious Diseases Society of America, 58, 928. https://doi.org/10.1093/cid/ciu012

[69] Kao, J.H., Jensen, D.M., Manns, M.P., Jacobson, I., Kumada, H., Toyota, J., et al. (2016) Daclatasvir plus Asunaprevir for HCV Genotype 1b Infection in Patients with or without Compensated Cirrhosis: A Pooled Analysis. Liver International, 36, 954. https://doi.org/10.1111/liv.13049 